\title{
O jogo como recurso pedagógico - Ser, comunicar, interagir, construir conhecimento
}

\author{
Estela Pinto Ribeiro Lamas \\ Universidade Metodista Unida de Moçambique
}

\begin{abstract}
Resumo
Para introduzir o simpósio, refletimos sobre o recurso à ludicidade, visando a construção de uma cultura que fuja à rotina e à instrumentalização, que promova o envolvimento dos alunos na aprendizagem, pelo prazer que esta lhes possa trazer. Exploramos possibilidades de transformar atividades pedagógicas rotineiras em jogo(s), que traga(m) ótimas experiências de aprendizagem ao(s) sujeito(s) implicado(s). Contextualizando as ideias apresentadas, abordamos teorias que sustentam a opção pelo jogo como recurso pedagógico-didático e questionamos as suas fundamentações científicas, visando criar condições para uma discussão construtiva sobre o potencial pedagógico do jogo para uma educação inclusiva e geradora de vivências interculturais positivas.

Palavras chave: educação, cultura, conhecimento, inclusão, jogo, representar
\end{abstract}

\section{Educação e ludicidade}

Ciente de que o jogo faz emergir e enriquecer a cultura do lúdico, como professora, apostamos em recorrer a ele como estratégia para um maior envolvimento dos alunos na aprendizagem. Com efeito, o jogo incentiva à interacção dos que nele participam e leva ao sentimento de pertença a um grupo, a uma comunidade; promove, de forma descontraída e divertida, a concentração na(s) actividade(s) que desencadeia. Muitos têm sido os pedagogos que enfatizam o contributo do jogo, ao longo dos tempos, como uma mais valia para a aprendizagem. A ludicidade é considerada indispensável não só para a educação, mas também para a socialização do ser humano. Na história da humanidade, a ludicidade não se restringe à infância; ela está presente na educação ao longo da vida.

Tendo por base a visão dualista razão/emoção, o jogo tem sido afastado do acto educativo; a denúncia e condenação desta atitude pragmática, acompanhada de reflexões sustentadas, traz para o palco das atenções a problemática que abordamos. Vasconcelos (2006, p.63), ao assumir que "o brincar, por ser considerado espontâneo, sentimental, romântico e natural, ficou excluído das instituições dirigidas à formação da razão" reforça essa condenação e abre vias e estimula para que a ludicidade esteja presente no mundo da educação. Reforçando a posição assumida por este autor, convocamos Gomes (2000, p.256):

o recurso a actividades lúdicas em domínios tão diversos (...) parece resultar, na maior parte dos casos, da necessidade de organizar um ensino e uma aprendizagem mais motivadores, mas tem igualmente a ver com a preocupação de evitar um corte radical entre as vivências eminentemente lúdicas da criança e o tipo de actividades educativas que a escola lhe propõe.
Consideramos, pois, que como professores devemos contribuir para que a ludicidade esteja presente em todos os níveis do ensino, no âmbito da educação formal e não formal, ou até mesmo no da educação informal. As boas práticas convocadas neste simpósio são contributos válidos que nos levam a repensar o valor pedagógico do jogo e o seu contributo para a criação de situações propiciadoras ao desenvolvimento do aluno, seja na sua forma de ser e estar - construindo a sua identidade -, de conviver - comunicando, interagindo -, seja ainda de conhecer - construindo conhecimento(s) e rentabilizando-o(s) em prol de si, do(s) outro(s) e da(s) comunidade(s) em que se integra.

\section{Conceitos e vivências}

Gomes, ao explorar o conceito do jogo, no Dicionário de Metalinguagens da Didáctica (Lamas (coord.), (2000, p. 253), remete-nos para as muitas áreas científicas que questionam a sua utilização: "a sociologia, a linguística, a estética, a teoria literária, a etnografia, os estudos sobre literatura para crianças e sobre expressão dramática, as teorias sobre a criatividade, a pedagogia em geral e a didáctica em particular”. Assim é de facto: a multiplicidade de enfoques, a que podemos ter acesso, permite que nos apercebamos do enorme valor educacional do jogo para o desenvolvimento holístico do ser humano.

Se bem que o termo latino ludus (jogo) esteja associado a ‘distração', palavra que geralmente é tomada no sentido negativo, importa perspetivá-la, aqui, num sentido positivo, isto é, ‘distração’ enquanto ‘abstração’, enquanto 'concentração de espírito’. Efetivamente, o jogo proporciona ao aluno a possibilidade de se abstrair de tudo o mais que o envolve, para se concentrar na(s) proposta(s) que lhe apresenta o educador. Nesse sentido é que o jogo, na antiga Grécia, era visto como o melhor caminho da educação, a via para atingir um fim, o de levar o ser humano à compreensão do que melhor lhe convém; evidenciamos: a sua compreensão, isto é, o que ele, na sua identidade, na especificidade da situação que vivencia, entende ser melhor para ele.

Este enfoque aponta a não instrumentalização da educação; a educação vista na dialética que decorre da relação entre educar e conduzir (para fora) - do latim 'educare' e '(ex)ducere'. Evidenciamos o duplo sentido que podemos atribuir à expressão 'para fora'; por um lado, o que propiciamos ao aluno descobrir dentro de si, as suas potencialidades, facilitando-lhe tirá-las 'para fora' e rentabilizá-las; por outro, fruto dessa descoberta e da sua rentabilização, a sua predisposição para se situar no mundo, melhor dizendo, a sua predisposição para a vida em sociedade. 
Bourdieu (1989) refere, em termos sociológicos, que o jogo está presente na aç̧ão intencional desenvolvida em sociedade, experimentada "por todos aqueles que entram no jogo" (p.79); a acção social resulta de "um senso prático como sentido do jogo, de um jogo particular, historicamente definido, que se adquire desde a infância, participando das actividades sociais” (p.81). Nessas actividades, a relação com o meio é também promovida: "[a]s ações realizadas pelas crianças no desenvolvimento do brincar proporcionam o primeiro contato com o meio, e as sensações que produzem constituem o ponto de partida de noções fundamentais e dos comportamentos necessários à compreensão da realidade” (Aguiar, 2006, p.23).

O conhecimento constrói-se nessa integração no meio, quando a sua compartimentação se desfaz, pelo enfoque interdisciplinar, que leva à com(a)preensão da realidade - a vivência transdisciplinar; é aí na vivência da realidade, na sua complexidade, que o ser humano fundamenta os saberes e os torna rentáveis para si, para o(s) outro(s), para a(s) comunidade(s). Entra, aqui, portanto, a dimensão etnográfica tão necessária em educação. O jogo viabiliza a integração dos alunos no(s) contexto(s) sociais, cultural(is), socioeconómicos diversificados; o recurso ao jogo, como estratégia de cariz etnográfico induz, pois, à interacção ser/contexto, à integração do ser no meio.

Convocamos, ainda, Carneiro (2011), que defende que a cultura assume uma dimensão poderosa na (re)construção do conhecimento e na sua partilha, suportada pelo jogo que reúne os sujeitos para uma aprendizagem partilhada, tal como a apresentamos neste simpósio. Complementando, esta ideia, Lamas (2011, pp.4707-08), por sua vez, defende que é "[n]a intersubjetividade gerada pela partilha e pela discussão, [que] a subjectividade sai enriquecida no e pelo confronto de ideias e de saberes catapultados para este espaço comum.”.

\section{Da interacção à descoberta do 'eu'}

Temos vindo a colocar em destaque o 'ser' e o seu desenvolvimento holístico, apontando para o contributo que o jogo pode trazer a esse desenvolvimento, quer em termos do ser, quer do estar e do (con)viver, na medida em que o envolve e o motiva, para se (con)centrar em determinada actividade; o (trans)forma. Há, pois, que explorar os contributos psicológicos pois, como Vygotsky (1996, pp.17-18) afirma:

o mecanismo da consciência de si mesmo (autoconhecimento) e do reconhecimento dos demais é idêntico: temos consciência de nós mesmos porque a temos dos demais e pelo mesmo mecanismo, porque somos em relação a nós mesmos o mesmo que os demais em relação a nós.

Para este autor, os sentimentos, as vivências emocionais estão intimamente relacionadas com os processos psicológicos e com a evolução da consciência; a tríade sentimento/emoções/consciência potencializa, com efeito as relações sociais e complementarmente, a interacção social potencializa a tomada de consciência e contribui definitivamente para a descoberta do 'eu', inter e intrapsicologicamente (Vygotsky, 2007).
O lúdico, na medida em que promove a interacção, desencadeia um processo de co-aprendizagem e tem presente os quatro eixos da educação recomendados por Delors (1996); ele propicia aprender a ser, aprender a estar e por inerência a (con)viver, aprender a conhecer e aprender a fazer. O companheirismo e, em consequência, a colaboração, que emerge naturalmente no acto do jogo, enquanto processo de co-aprendizagem, e desencadeia em paralelo, um processo de emancipação do 'eu', já que, nele e por ele, o ser aprende a aceitar as perdas/derrotas ou fracassos, aprende a ponderar os desafios com que se confronta, aprende a ponderar as hipóteses diversificadas que surgem, aprende a explorar a espontaneidade, expressar a criatividade. É no percurso partilhado com o outro, feito ao longo do processo de co-aprendizagem - co-construção de conhecimentos e de sentidos, nas mudanças planificadas e nas que vão surgindo inesperadamente, que a emancipação do 'eu' acontece; emergem, então, a confiança, a maturidade, a segurança, a autonomia, a responsabilidade, a(s) competências inerentes à formação comos ser humano.

É, também, nesse processo e nesse encadeamento de performances diversificadas que a possibilidade do exercício de concentração, de atenção e de socialização acontece. O jogo é essencial para que o ser humano utilize as suas potencialidades de maneira integral, descobrindo o seu 'eu'.

O potencial pedagógico do jogo. A pedagogia lúdica justifica-se, então, por várias razões, uma vez que o jogo, embora seja reconhecido como um modo de ser existencial do homem e dos animais superiores, só a nível humano se regista como actividade criadora. Verificamos, também, que a arte, a ciência e a própria religião são muitas vezes assumidas como jogos tomados no seu mais profundo sentido; o jogo aparece como a primeira forma encontrada pelo recém nascido para comunicar com a mãe; a criança aprende jogando (experiências vivenciais); o ser humano joga criativa e livremente; o jogo abre horizontes de possibilidades.

Para conhecer as capacidades do aluno e compreender as suas motivações, o professor empenha-se em proporcionar-lhe oportunidades de revelar as suas potencialidades, as necessidades psicológicas inatas; só assim o professor pode criar condições ao aluno, para o desenvolvimento de competências, para a conquista da autonomia, para um relacionamento positivo com os seus pares. O professor contribui desse modo para que o aluno construa a sua identidade, através de formas específicas de ser, comunicar, interagir, construir conhecimento.

Ao apostarmos no lúdico como recurso pedagógico, envolvendo os alunos na e pela brincadeira, não perdendo a seriedade de que, como qualquer factor de aprendizagem, se deve revestir, estaremos nós professores a criar condições não só para aprendizagens significativas, mas também, em simultâneo, para o confronto do ser consigo próprio, para o seu desenvolvimento integral - motor, cognitivo, afetivo e social. Como diz M. Lamas (2015, p.11), pela relação empática estabelecida,

assim se impulsiona o desenvolvimento de competências de cooperação, de colaboração, de (auto)regulação, de (inter)subjetividade, de interiorização de coordenações 
sociais, procurando reforçar a cognição através do conflito sociocognitivo, pela conciliação de diferentes pontos de vista, pela construção partilhada do saber, pelo desenvolvimento da reflexão e do pensamento crítico, pela co-construção de conceitos e abstração, pela (re)estruturação mental e aplicação prática, levando a um maior empenhamento nas tarefas de aprendizagem.

\section{Boas práticas}

Por boas práticas entendemos experiências realizadas, que merecem ser partilhadas e divulgadas pelos bons resultados alcançados, potenciando a aprendizagem e levando ao questionamento dos princípios que as orientam, à discussão dos meios utilizados, ao aprimoramento das actividades/estratégias a que recorrem; os princípios orientadores das boas práticas, segundo Bezarra (2007), são a abertura à mudança e a qualidade dos resultados alcançados. $\mathrm{O}$ processo que se desencadeia a partir da partilha, do questionamento, da discussão subsequente, visa incentivar à implementação de outras experiências similares, mas particulares, pensadas em função dos intervenientes a envolver - os seus perfis específicos, as suas capacidades, as suas limitações - e tendo em conta os contextos em que possam vir a ter lugar - culturais, sociais, económicos.

Os esquemas apresentados na Figura 1 e na Figura 2 enfatizam o conceito de 'boa prática', conforme se deve entender no mundo da educação. Esse conceito, conforme sugerem os autores,

implica inovação, criatividade e originalidade; exige eficiência, actualidade, utilidade, flexibilidade; recorre a metodologias sólidas e (com)provadas; apoia-se em estratégias eficientes e em bons procedimentos; promove o trabalho de equipa, igualdade de oportunidades e mudança abre expectativas e vias para o sucesso; pressupõe (re)adaptação e transferibilidade.

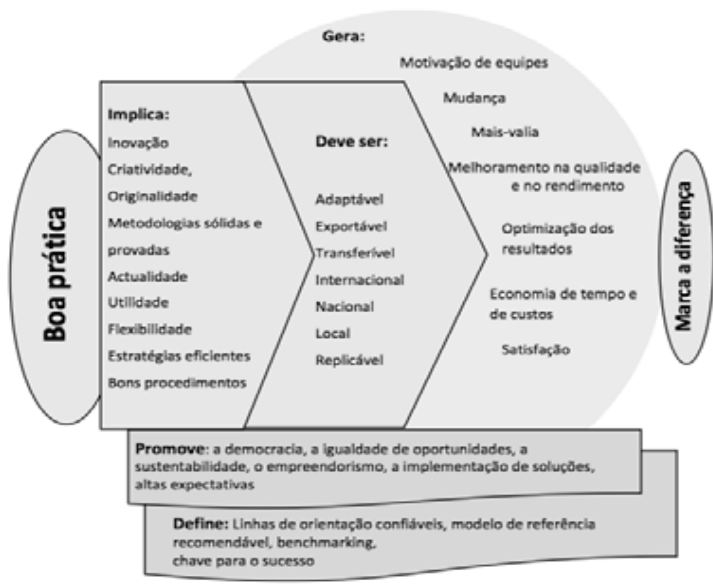

Figura 1. Boa prática (Flores, Escola e Peres, 2009)

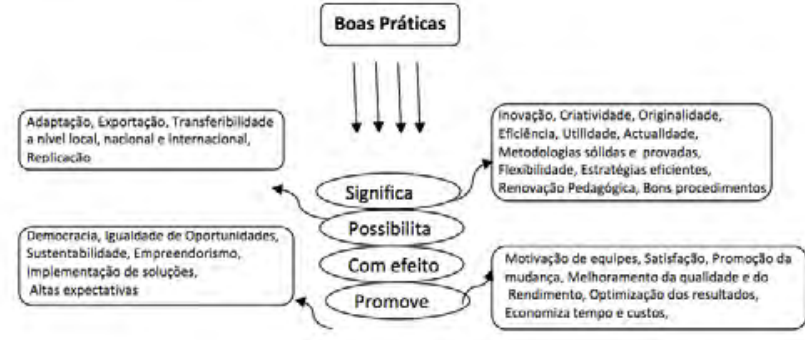

Figura 2. Boas práticas (Flores, Escola e Peres, 2010)

Na nossa óptica, esse conceito está subjacente às boas práticas que partilhamos neste simpósio, boas práticas essas que, pela sua diversidade, quer em termos de áreas científicas, quer em termos de metodologias, quer ainda de estratégias, actividades e procedimentos, oferecem um manancial para o reforço da nossa profissionalidade a aprendizagem ao longo da vida que, como profissionais de docência, devemos procurar.

Reconhecemos a pertinência e a actualidade das temáticas abordadas, a utilidade das propostas pedagógicas, a flexibilidade de que se revestem e a abertura de oportunidades de transferência da boa prática em causa, para outros contextos e para o envolvimento de outros actores, portanto, a sua (re)adaptação noutros momentos e mesmo noutras áreas do saber. As boas práticas partilhadas revelam eficiência profissional, preocupação com o sucesso educativo dos alunos, com 0 seu desenvolvimento integral.

O jogo e as expressões artísticas. A primeira comunicação explora num primeiro momento a sustentação teórica da opção da autora que focaliza o jogo no campo das expressões integradas, revelando o seu potencial sócio-lúdico, explorando estratégias diversificadas que proporcionam o trabalho individual, em grupos e em comunidade. Realça o jogo performativo que viabiliza o experienciar e o manusear de signos de tipo corporal, espacial, sonoro integrado. Alerta-nos, também, para a ampliação e mutação hodiernas e expressivas, mediadas pelas tecnologias. Realça a 'artitude', ao denotar a tríade corpo-ambiente-acção assumida pelo indivíduo e evidencia, entre outras, as mais-valias patrimonial, cultural, autobiográfica para a construção de materiais didácticos e lúdicos.

O jogo e o drama. A segunda apresentação centra-se no drama e questiona o seu contributo para a educação e para o desenvolvimento da criança, salientando a forma como a impele a autodescobrir-se, a partilhar as suas opiniões e emoções, servindo assim para a sua socialização. Enfatiza a procura do equilíbrio metodológico para perspetivar o drama e o teatro como experiências educativas complementares, envolvendo assim, de forma natural, as crianças no brincar dramático, induzindo-as numa natural aquisição das técnicas e convenções teatrais, no envolvimento com a arte, potenciando o seu desenvolvimento holístico sentimento, emoção, auto-conhecimento, pensamento, conhecimento, interacção com o(s) outro(s).

O jogo e a música. A terceira partilha apresenta a vivência de um projeto que evidencia o contributo da música para a formação holística da criança; mostra 
como o envolvimento se processa em todo o seu esplendor, pelo canto, pela dança, pela audi(a)ção, pelo jogo e pela leitura. Percorre, de forma atractiva as novas formas de ensinar música - o movimento, a voz e audição, o teatro musical, o jogo posto em destaque como forma de envolver a criança pela brincadeira. Culmina com a referência ao workshop da Musicraft que põe em prática as formas de ensinar música apresentadas e discutidas, partindo da exploração de uma história. O desafio lançado é o do recurso ao jogo e à componente lúdica como base de sustentação de uma educação musical e artística de qualidade para as crianças de hoje, adultos de amanhã.

O jogo e a língua. A quarta comunicação explora a potencialidade da poesia para a promoção do desenvolvimento holístico da criança. Partindo do conceito polissémico de 'poesia', esta é associada ao 'jogo' que permite explorar de forma experiencial as potencialidades deste género literário. Parte então para vivências ricas do domínio poético que não só viabilizam a aprendizagem da língua, promovem a escrita criativa, estimulam a imaginação e a criatividade da criança. A abordagem da poesia de forma lúdica suscita, pois, por um lado, a emoção, o sonho, o encantamento e, por outo, leva à construção de uma relação efectiva da criança com o mundo. Ela propicia, através do jogo, a apropriação da linguagem, a formação da personalidade da criança. Tendo por sustentáculo estes pressupostos teóricos, são apresentadas as três fases de envolvência da poesia em contexto de sala de aula, cuja finalidade é induzir o gosto pelo texto poético - a da metapoesia, a da produção e a da visibilidade.

\section{Questões conclusivas / projectivas}

Importa, pois, que nos empenhemos em dar um novo significado ao espaço da sala de aula, nela integrando o lúdico, ciente do seu valor enquanto elemento facilitador e mediador pedagógico. Sistematizando, podemos avançar com algumas ideias que foram surgindo e que entendemos serem orientadoras da acção que nos propomos como professora, uma acção que, pelo recurso ao jogo, à brincadeira, potencie o desenvolvimento holístico do ser humano, que leve a criança a aprender a ser, a comunicar, a interagir, a construir conhecimento.

Através das reflexões aportadas pelos diferentes intervenientes deste simpósio, através da partilha da(s) sustentação(ões) teórica(s) problematizada(s), através das boas práticas referenciadas, cremos que se colocam, em termos projectivos, desafios positivos que poderão levar à implementação de boas práticas que façam uso do lúdico, não só em ambiente de sala de aula, isto é, no âmbito da educação formal, mas também da educação não formal e informal. Não são apenas os conteúdos programáticos que estão em causa, é a cultura, é o património, é a vida em sociedade.

O 'eu' revela-se no seu todo, através da interacção que possa vir a ser estabelecida com os seus pares, em contexto escolar, mas também, com outros actores de outros contextos com os quais venha a interagir e nos quais possa vir a integrar-se. A exploração das potencialidades do jogo contribuirão para que essa interacção seja real e tenha consequências positivas para a educação do ser humano.

\section{Referências}

Aguiar, O. P. (2006). Reelaborando conceitos $e$ ressignificando a prática na educação infantil. Tese de doutoramento em Educação. Natal: Universidade Federal do Rio Grande do Norte. Disponível em repositorio.ufrn.br:8080/jspui/handle/123456789/141 16 acedido em Maio de 2010.

Bezara, M. (2007). Buenas prácticas en el practicum: bases para su identificación y análisis. In T. E. (Ed.) El practicum: buenas prácticas en el Espacio Europeo de Educación Superior (pp. 7-33). Vigo: Universidad de Vigo.

Bourdieu, P. (1989). O poder simbólico. Lisboa: Difel.

Carneiro, R. (2011). Discovering the Treasure of Learning. In Conceptual Evolution and Policy Developments in Lifelong Learning. Hamburgo: UNESCO,

Delors, J. (coord.). (1996). Educação, um Tesouro a Descobrir. Porto: Edições ASA.

Flores, P. Q., Escola, J. e Peres, A. (2009). A Tecnologia ao serviço da educação; prática com TIC no $1^{\circ}$ Ciclo do Ensino Básico. In Conferência Internacional de TIC na Educação - Challenges, pp.715-726. Braga: UM. Disponível

em http://recipp.ipp.pt/bitstream/10400.22/6332/1/AR T_PaulaFlores_2009.pdf acedido em Janeiro de 2011.

Flores, P. Q., Escola, J. e Peres, A. (2010). A concepção de boas práticas segundo os professores do $1^{\circ}$ Ciclo do Ensino Básico. In $8^{\circ}$ Cogresso LUSOCOM, pp.5175-5189. Lisboa: Universidade Lusófona de Humanidade e Tecnologias. Disponível em http://conferencias.ulusofona.pt/index.php/lusoco m/8lusocom09/paper/viewFile/436/434 acedido em Junho de 2011.

Gomes, J. A. (2000). Jogo. In E. Lamas (2000). Dicionário de Metalinguagens da Didáctica, pp.253-256. Porto: Porto Editora.

Lamas, E. (coord). (2000). Dicionário de Metalinguagens da Didáctica. Porto: Porto Editora.

Lamas, E. (2011). Symposium - Perspectiva Dialógica Interdisciplinar - Para uma Aprendizagem Contextualizada, Activa e Signficativa. In Libro de Actas do XI Congreso Internacional Galego-Portugués de Psicopedagoxía (pp. 4705-4715). Coruña: Universidade da Coruña.

Lamas, M. (2015). A formação de Professores em Empreendedorismo no contexto do Ensino Superior. Relatório de pós-doutoramento. Porto: FPCEUP.

Vasconcelos, M. S. (2006). Ousar brincar. A. Arantes (Org.). Humor e alegria na educação. São Paulo: Summus.

Vygotsky, L. (1996). Os métodos de investigação reflexológicos e psicológicos. Teoria e método em psicologia. São Paulo: Martins Fontes.

Vygotsky, L. (2007). Pensamento e Linguagem. Lisboa: Edições Piaget. 